Bush administration announced that Crawford would be replaced on an acting basis by Andrew von Eschenbach - who would also continue to serve as director of the National Cancer Institute (NCI), a massive research agency with a stake in some of the FDA's toughest regulatory decisions. Last Friday, von Eschenbach admitted that this would be impossible, and said he would temporarily shelve his daily duties at the $\mathrm{NCI}$ and excuse himself from some cancer-related activities at the FDA (see page 802 ).

Crawford's record as acting and then permanent head of the FDA was underwhelming. He had little public visibility and seemed reluctant to back up his own scientific advisers when their advice ran counter to Bush administration doctrine, for example to make Plan B, the morning-after contraceptive, available over-the-counter from pharmacists (see Nature 437, 179; 2005). Now his departure is being left wholly unexplained, prompting reports of financial conflicts, as well as a bipartisan congressional investigation.

It is not clear that von Eschenbach can do much better. The 63year-old urology surgeon has exasperated NCI researchers by making it a goal to end suffering and death from cancer by 2015 - an improbable aim he describes as "within our grasp". His public commitment to more rapid approval of experimental cancer treatments also deserves close examination in the light of several drug withdrawals, for safety reasons, in the past year alone.

In his three years at the NCI, he has become known as a hands-off manager who leaves the workings of bureaucracies under him largely to subordinates. This is not the prescription for an agency that has been rocked by serious crises and that now needs a leader with a firm grasp of policy details that ultimately affect millions of lives.

Yet if past inattention is any indication, it seems likely that the White House will leave von Eschenbach - a Bush family friend holding the fort at the FDA while it is preoccupied elsewhere. That would leave an agency that has lacked a permanent head for most of Bush's presidency in limbo yet again. Three years ago, a government survey of $400 \mathrm{FDA}$ scientists found $18 \%$ of them reporting that they "have been pressured to approve or recommend approval" for a drug "despite reservations about the "This is not the prescription for an agency that has been rocked by serious crises and nowneeds a leader with a firm grasp of policy details." safety, efficacy or quality of the drug". In the absence of firm leadership, scientists at the FDA's headquarters in the Washington DC suburbs will be left to do battle with ideologues such as Scott Gottlieb, a 33-year-old physician and former Wall Street tipster who was appointed in July as deputy commissioner for medical and scientific affairs at the agency.

Perhaps the most worrying prospect is that of an agencyleft to drift and further neglect under a stop-gap commissioner for another three years, until Bush has served out his term. His administration needs to find a well-qualified, permanent FDA commissioner - and soon. -

\section{Welcome Nature Physics}

\author{
The launch of a new Nature journal comes at an \\ exciting time for physics.
}

$\square$ eople have stopped talking about 'physics envy'. Time was when other sciences were jealous of the prestige and funds attracted by physics, and also of its success in capturing the imagination, as it uncovered revolutionary ways of thinking about, and predicting, the constituents and governing principles of the Universe.

Nowadays, thanks to the allure of biology's progress and benefits, physics is just another discipline. But its decline in prominence should not mislead. The next generation of particle accelerators promises insights as deep as any of their predecessors, in particular in understanding the origins of mass and the symmetries underlying the laws of nature. The enduring conjugal relationship between physics and mathematics continues to stimulate both. Understanding the behaviour of electrons and light within condensed matter continues to yield not only surprises in understanding but also new technologies. And physicists' habit of thinking about the underlying questions leads them still to speculate beyond the current limits of experiment. Where does quantum mechanics fail? Is information a more fundamental quantity than hitherto realized?

It is with the enduring enticement of these challenges in mind that we welcome the launch this month of our sister publication Nature Physics (www.nature.com/naturephysics). It is also an indicator of success. After the Second World War, Nature ceased to be a vehicle for the physics community. It was only after the advent of high- temperature superconductivity that physicists began to rediscover the journal's value. Over the succeeding two decades or so, Nature has re-established itself as a prime physics outlet.

At the same time, the publishing habits of physicists have also evolved. Preprint servers are now commonplace for some branches of the subject, without damaging journals. The number of papers published has grown by $3 \%$ per year, but there have been significant shifts in regional output. Between 1981 and 2001, US research output in physics fell by $1.5 \%$ (to 19,500 papers per year), Western Europe saw research output grow by $56 \%$ (to 29,100 papers), and output in Asia grew by $120 \%$ (to 22,500 papers). Within Asia, China saw its output grow from 500 articles to 5,500 , Japan's grew by $67 \%$ to 11,000 and India saw a $40 \%$ increase to 2,100 papers.

Perhaps the most significant shifts are in the distribution of the physics community over that period, with the number of $\mathrm{PhDs}$ in physics declining markedly in the United States and Europe but increasing dramatically in Asia. Nature and its related journals have
"Experience has shown that launching sibling research journals strengthens Nature. More importantly, it stimulates the discipline." always had internationalism as a key ingredient, and have reflected regional growths in strength.

Experience has shown that launching sibling research journals strengthens, rather than weakens, Nature. More importantly, it stimulates the discipline by providing greater exposure thanks to our media and web strengths, and, above all, by providing healthy competition to established journals, to the benefit of authors and readers everywhere. Nature Physics is set to follow this tradition. 